\title{
ANALYSIS OF STABILITY OF WIND BASED DISTRIBUTED ENERGY GENERATION SYSTEM
}

\author{
Namra Joshi ${ }^{1 *}$, Pragya Nema ${ }^{2}$ \\ ${ }^{1}$ Research Scholar, Department of Electrical \& Electronics Engineering, Oriental University, Indore, \\ Madhya Pradesh, India \\ ${ }^{2}$ Professor \& Head, Electrical \& Electronics Engineering, Oriental University, Indore, Madhya \\ Pradesh, India, dr.pragranema @ymail.com \\ *Namra Joshi; er.nrjoshi@gmail.com
}

\begin{abstract}
Wind energy generation, utilization and its grid penetration in electrical grid are increasing worldwide. The wind generated power is always fluctuating due to its time varying nature and causing stability problems. This weak interconnection of wind generating source in the electrical network affects the power quality and reliability. The influence of the wind turbine in the grid system concerning the power quality measurements are the variation of voltage, flicker, harmonics. This paper highlights a brief overview of the stability issues related to integration.
\end{abstract}

Key words: Renewable Energy; Distributed Generation; Wind Energy; Harmonics; Grid Stability

\section{INTRODUCTION}

Wind power has become the world's rapid growing renewable energy source. The many advantages of the wind energy are clean energy, economic development, environmental protection, diversity of the supply, rapid spread, transference and technological innovation, industrial scale electricity in network and the fact is that the wind does not pollute, it is abundant, free and unlimited. Wind Energy penetration in India has seen robust growth over the past decade $\&$ stands $5^{\text {th }}$ in the world. Armed with the necessary experience, the finer aspects related to its deployment and performances are now gaining visibility \& attention. [2]

The important parts of a wind turbine system [3] like turbine rotor, gearbox, generator, power electronic system, and a transformer for grid connection are illustrated in figure below. Wind turbines obtain the power from wind by means of turbine blades and it's converted to mechanical power. It is necessary to control and limit the converted mechanical power during higher wind speeds. The general way to convert the low-speed, high-torque mechanical power to electrical power is using a gearbox and a generator with standard speed. The gearbox connects the low speed of the turbine rotor to the high speed of the generator, \& gearbox is not being essential for multi pole generator systems. Then the generator converts the mechanical power into electrical power, which is fed into a grid by processed through power electronic converters, and a transformer with required protection \& metering equipments. Generally induction generators \& synchronous generator are used in wind turbines. 
Induction generators [4] produce electrical power when its shaft is rotated faster than the synchronous frequency of the equivalent induction motor. As these generators have ability to produce power at varying rotor a speed that's why they are used in wind turbines. Induction generators are mechanically and electrically simpler than other generator types. They are also more rugged, requiring no brushes or commutators. They are not self-exciting, means they require an external supply to produce a rotating magnetic flux. The external supply can be supplied from the electrical grid or from the generator itself, when it starts producing power. The rotating magnetic flux from the stator induces currents in the rotor, which also produces a magnetic field. If the rotor turns slower than the rate of the rotating flux, the machine acts like an induction motor. Rotor is turned faster; it acts like a generator, producing power at the synchronous frequency. In this type of generators the magnetizing flux is established by a capacitor bank connected to the machine in case of standalone system and in case of grid connection it draws magnetizing current from the grid. It is mostly suitable for wind generating [6] stations as in this case speed is always a variable factor.

Mechanical power

Electrical Power

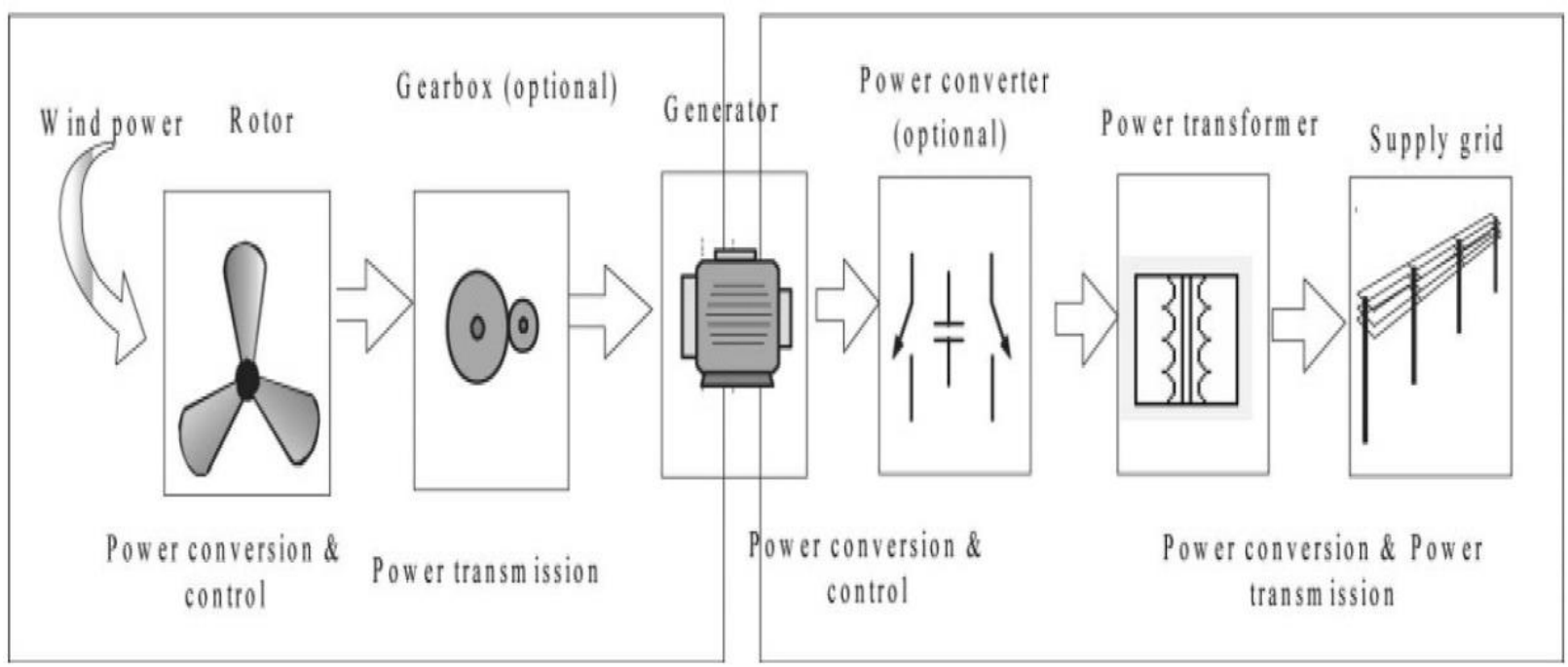

Fig. 1 Wind Turbine System [2]

Synchronous generator runs at a constant speed and draws its excitation from a power source external or independent of the load or transmission network it is supplying. It has an exciter that enables it to produce its own "reactive" power and to also regulate its voltage. They can operate in parallel with the utility or in "stand-alone" or "island" mode. It requires a speed reduction gear. To increase power reliability power plants that have synchronous generators are preferred. [3]

In the past, wind turbine generators [6] were disconnected from the system during abnormal conditions like faults. Now with the increasing requirement for wind power to remain connected to the power system during faults, since the wind power lost might affect the system stability Therefore, the wind turbine behavior during system performance and its influence in the system protection must be analyzed. One of the most frequent irrelevant features about integrating wind energy into the electricity network is that it is treated in isolation. An electricity system in practice is modify like a big bath tub, with hundreds of taps (power stations) providing the input and millions of plug holes (consumers) draining the output. The taps and plugs are opening and closing at all the time. For the grid operators, the task is to make sure there is enough water in 
the tub to maintain system security. It is therefore the combined effects of all technologies, as well as the demand patterns, that matters. [5]

\section{DISTRIBUTED GENERATION}

Distributed Generation [1] is defined as installation and operation of small modular power generating technologies that can be combined with energy management \& storage systems. It is used to improve the operations of the electricity delivery systems at or near the end user. These systems may or may not be connected to the electric grid.

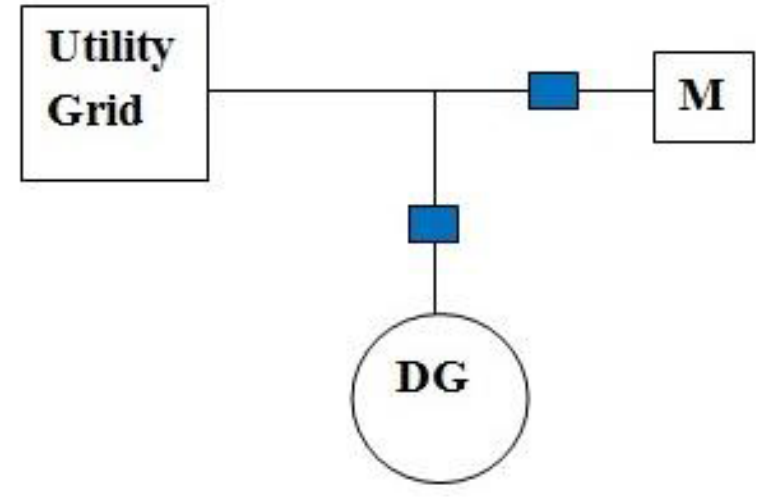

Fig. 2 Interconnection of DG

A distributed generation [1] system can employ a range of technological options from renewable to non-renewable and can operate either in a connected grid or off-grid mode. The size of a distributed generation system typically ranges from less than a kilowatt to a few megawatts. Distributed resources can either be grid connected or independent of the grid. Those connected to the grid are typically interfaced at the distribution system.

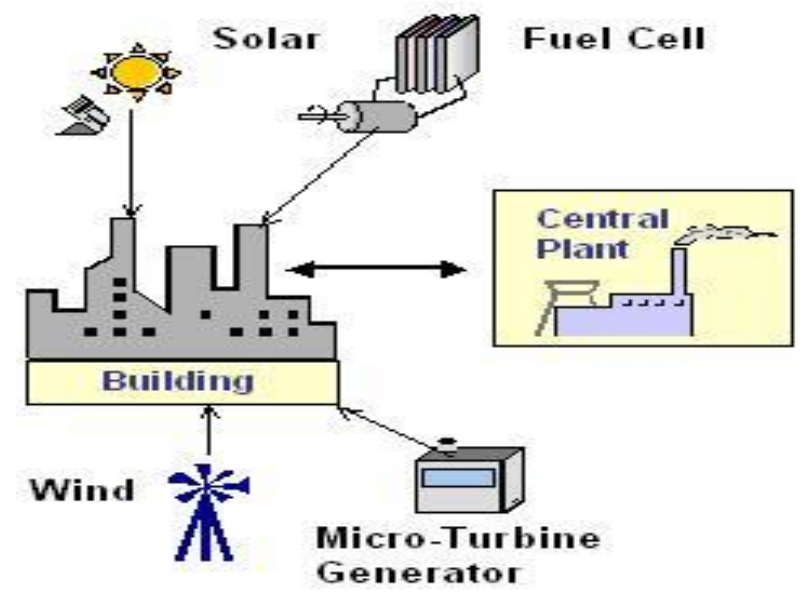

Fig. 3 Distributed Generation

\subsection{Classification of Distributed Generation}

Distributed Generation [1] are classified on three basis: 


\subsubsection{On the basis of Generation technology:}

- Conventional Type: In this type of distributed generation system conventional energy sources like Diesel engines with very large storage tanks(five days are common), Reciprocating engines similar to diesels that burn natural gas from a pipeline, Micro turbines on natural gas are used.

- Non Conventional Type: In this type of distributed generation system non conventional energy sources like wind energy, solar energy, biomass \& hydro energy are used.

\subsubsection{On the basis of Connection:}

- Isolated Type: This type of distributed generation system are not connected with grid.

- Grid Connected: This type of distributed generation system are not connected with grid $\&$ bidirectional power flow is possible.

- Captive Type: This type of distributed generation system operates in isolation from the national or local electricity distribution network.

- Cogeneration Type: In this type of distributed generation system electricity \& useful heat is generated at the same time.

- Stand by Type: This type of distributed generation system operates in case of emergency.

\subsubsection{On the basis of Size:}

Table I Size Of Distributed Generation

\begin{tabular}{|l|l|}
\hline \multicolumn{1}{|c|}{ Type } & \multicolumn{1}{c|}{ Size } \\
\hline Micro Distributed Generation & $1 \mathrm{Watt}<5 \mathrm{MW}$ \\
\hline Small Distributed Generation & $5 \mathrm{KW}<5 \mathrm{MW}$ \\
\hline Medium Distributed Generation & $5 \mathrm{MW}<50 \mathrm{MW}$ \\
\hline Large Distributed Generation & $50 \mathrm{MW}<300 \mathrm{MW}$ \\
\hline
\end{tabular}

\subsection{Current Scenario of Distributed Generation in India}

Over the years, renewable energy sector in India has emerged as a significant player in the grid connected power generation capacity. It supports the government agenda of sustainable growth, while, emerging as an integral part of the solution to meet the nation's energy needs and an essential player for energy access. It has been realized that renewable energy has to play a much deeper role in achieving energy security in the years ahead and be an integral part of the energy planning process. Wind energy has emerged as most successful renewable energy option in India and is the fastest growing renewable energy technology for generating grid connected power amongst various renewable energy options. The Ministry's wind power programme covers wind resources assessment, facilitation of implementation of demonstration and private sector projects through various fiscal and promotional policies. A total capacity of 28700.44 MW has been established up to December, 2016 in the country. India is the fourth largest wind power producer in the world, after China, USA and Germany.[29] 


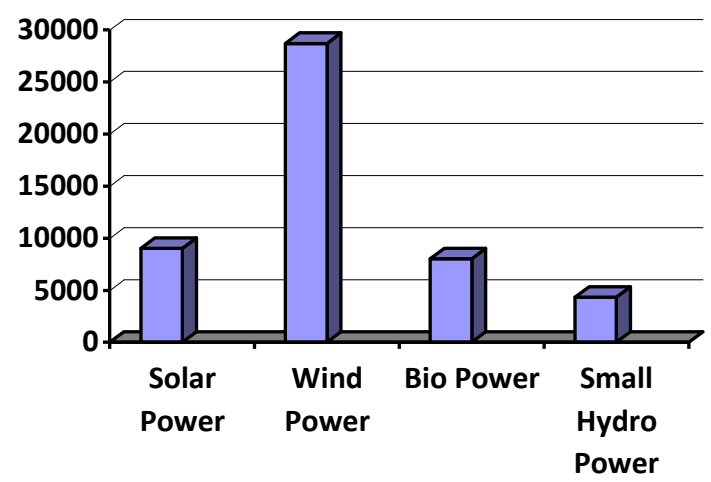

Fig. 4 Sector-Wise Installed Capacity of Renewable Energy in India [29]

\section{IMPACT OF INTERCONNECTION ON GRID STABILITY}

The connection of large wind turbines to the grid has large impact on grid stability [4]. The increased penetration of wind energy into the power system over the last decade has therefore led to serious concern about its influence on the dynamic behavior of the power system. The main attention in the grid requirements is drawn to the fault ride-through and power control capabilities of large wind farms. The different characteristics from the different grids in each country cause that the behavior of the wind farm has greater or smaller influence in the stability of the system. For that reason the demanded requirements vary from one country to other and there are international organisms that work on surrounding of requirements that include the different exigencies [19]. The squirrel cage induction generator of the constant speed systems always consumes reactive power. The consumption depends on the voltage and generated active power. In most of the cases this consumption is compensated by capacitors. By adding capacitors the impact of the wind generator is reduced. However, controllable reactive power sources are needed to fulfill the requirements, such as switched capacitor banks, STATCOM and SVC. $[4,12]$

\section{A. Fault ride-through capability}

The fault ride-through requirement has been imposed in order to avoid significant loss of wind turbine production in the event of grid faults. Earlier, wind turbines were only required to be disconnected from the grid when a grid fault was detected, in order thus to avoid large inrush currents when the voltage recovered. However, with the increased capacity of wind power in the power system over the years, such a disconnection of wind turbines could generate control problems of frequency and voltage in the system, and as worst case a system collapse. [25]

\section{B. Power Control Capability}

The power control ability means mainly that the wind turbines have to share, for shorter or longer periods, some of the duties carried out traditionally by conventional power plants, such as regulating active and reactive power and performing frequency and voltage control on the 
grid. These requirements refer to the ability of wind farms to regulate (usually, but not exclusively, reduce) their power output to a defined level (active power curtailment), either by disconnecting wind turbines or by pitch control action. [26]

\section{Voltage Stability}

Some grid codes prescribe that wind farms should support the grid by generating reactive power during a network fault, to support and restore fast the grid voltage. Wind farms support grid voltage with additional reactive current during a voltage dip, as well as via increased reactive power consumption in the event of a voltage dip[18]. The voltage control must take place within $20 \mathrm{~ms}$ (one cycle) after fault recognition by providing additional reactive current on the lowvoltage side of the wind turbine transformer, amounting to at least $2 \%$ of the rated current for each percent of the voltage dip.[27,28]

\section{STABILITY FACTORS FOR INTERCONNECTION OF WIND FARM TO GRID}

\section{A. Harmonics}

Harmonics can be injected both at the utility and the consumer end. At the consumer end, harmonics are usually caused due to use of non linear loads such as television, personal computers, compact fluorescent lamps etc. The harmonics distortion caused by non-linear load such as electric arc furnaces, variable speed drives, large concentrations of arc discharge lamps, saturation of magnetization of transformer and a distorted line current. The effect of harmonics in the power system can lead to degradation of power quality at the consumer's terminal, increase of power losses, and malfunction in communication system [5]. The degree of variation is checked at the PCC, where consumer and utility area of responsibility meet. The harmonics voltage and current should be limited to acceptable level at the point of wind turbine connection in the system. As per standard IEC61400-21 guideline, harmonic measurements are not required for fixed speed wind turbines where the induction generator is directly connected to grid. Harmonic measurements are required only for variable speed turbines equipped with electronic power converters. In general the power converters of wind turbines are pulse-width modulated inverters, which have carrier frequencies in the range of $2-3 \mathrm{kHz}$ and produce mainly inter harmonic currents. The harmonic measurement at the wind turbine is problem due to the influence of the already existing harmonic voltage in the grid. The wave shape of the grid voltage is not sinusoidal. There are always harmonics voltages in the grid such as integer harmonic of 5 th and 7 th order which affect the measurements.

\section{B. Voltage Sag \& Swell}

Voltage sag is a short duration phenomena in power system in which RMS voltage magnitude decreases between 10 and 90 percent of the nominal RMS voltage at the power frequency, for durations of 0.5 cycles to 1 minute as shown below. 

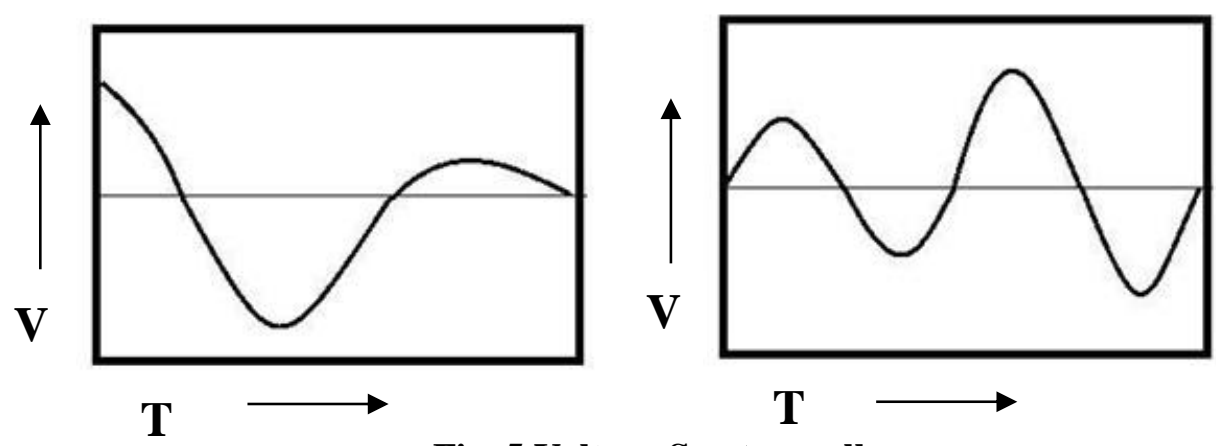

Fig. 5 Voltage Sag d s well

The voltage sag occurs due to faults on the transmission or distribution network (most of the times on parallel feeders). It also occurs due to faults in consumer's installation, connection of heavy loads and startup of large motors. The voltage swell is momentary or sudden increase of the RMS voltage, at power frequency outside the normal tolerances, with duration of more than one cycle and typically less than a few seconds. It originates due to start/stop of heavy loads, badly dimensioned power sources, badly regulated transformers (mainly during off-peak hours). [6,7]

\section{Voltage Interruptions}

A voltage interruption (IEEE Std. 1159), supply interruption (EN 50160), or just interruption (IEEE Std.1250) is a condition in which the voltage at the supply terminals is close to zero. As per IEEE, Close to zero means lower than 10 percent of its nominal supply. The Voltage interruptions can be for short duration or long duration. They are initiated due to tripping or failure of protection devices. If the voltage supply interruption occurs from few milliseconds to one or two seconds, it is called short duration interruption. If the supply voltage interruption persists for greater then one or two seconds, it is called long duration interruption. [6] [7]
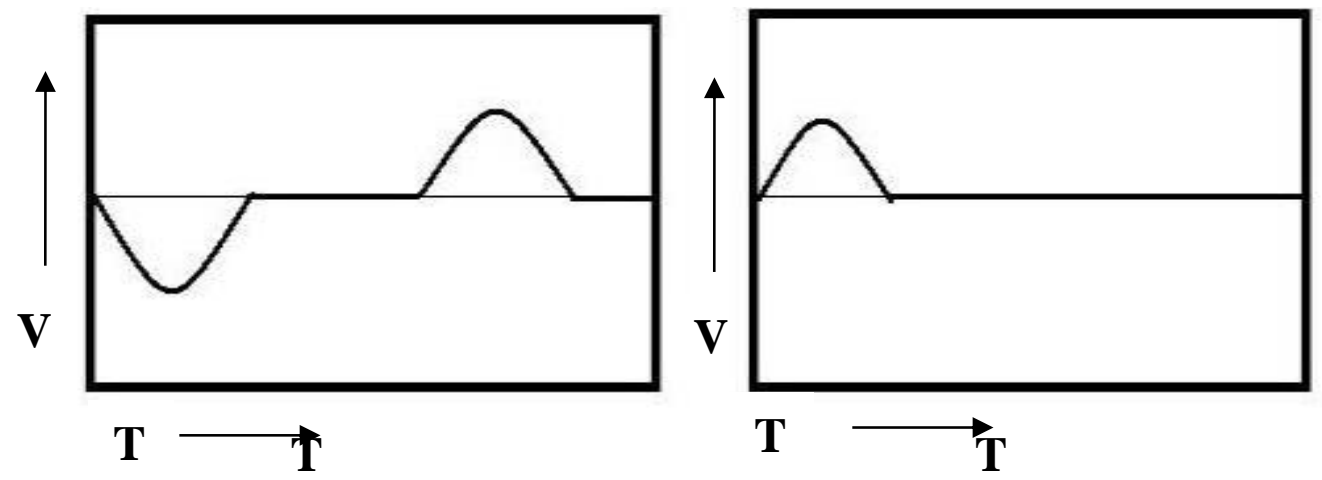

Fig. 6 Voltage Interruption

\section{Flickers}

Flickers are the periodic voltage frequency variations typically between 0.5 and $25 \mathrm{~Hz}$ that cause annoyance from the incandescent bulb [8,9]. Flicker annoyance is severe at a frequency of $8.8 \mathrm{~Hz}$ [8]. The international electrochemical commission (IEC) standard 61000-4-15 describes the measurement of flicker given the instantaneous flicker level (IFl) as well as the probability 
short term (Pst) measure for a time span of $10 \mathrm{~min}$, and the probability long term (Plt) measured for an average of 2 hours. For flicker free voltage, Pst $=0$. A Pst=1 indicates that the flicker pollution has reached the tolerable limit of an average person. The flicker level for a mediumvoltage grid is specified by 0.35 (Pst) and $0.25(\mathrm{Plt})$.

The wind generators sometimes produce oscillatory output power, which could cause flickers in the power system network. The fluctuation caused by the tower shadow and turbulence effect in wind may cause flickers. IEC 61400-21 furnishes the measurement procedure to calculate the flicker impact of wind turbines. According to this standard, the voltage fluctuation by the wind turbine is divided into two components: the continuous operation and the switching operation. Voltage fluctuations due to continuous operations result from the variation of active and reactive power due to the fluctuation in wind speeds ( $3 p$ effect in fixed speed wind turbines) [8], whereas variable speed wind turbines have the ability to absorb the $3 p$ effect by mean of a small change in their rotor speed. Switching operations are caused by fast changes of power from one level to another which could be due to generator cut-in, cut-out and switching between wind generators. [22]

The effects of flickers are generally not severe in variable speed wind turbines unlike in fixed speed wind turbines. This is because the variable speed wind turbines have the ability to provide speed controls to damp the fluctuations of the aerodynamic torque emanating from switching operations or changes in wind speed therefore mitigating flickers [10]. Both the continuous operation flicker coefficient and the flicker emission due to the switching operations of the wind turbines are provided based on the network impedance phase angle and 10-minute average wind speed [11-13].

\section{E. Harmonic Distortion}

Voltage and current harmonics and sub-harmonics: It corresponds to the supply voltage or current waveforms of non-sinusoidal shape. The waveform corresponds to the sum of different sine waves with different magnitude and phase, having frequencies that are multiples of power system frequency as shown in Fig.2-A. Harmonic distortion causes due different types of nonlinear loads like arc furnaces, welding machines, rectifiers, switched mode power supplies, data processing equipment etc. A common term that is used in relation to harmonics is called as THD or Total Harmonic Distortion [7]. The term THD is used to describe voltage or current distortion and is calculated using Eq 1. [7, 14]:

$$
\% \mathrm{THD}=\sqrt{\mathrm{I}\left(\mathrm{D}_{1}\right)^{2} \pm \mathrm{I}\left(\mathrm{D}_{2}\right)^{2}+\ldots m \ldots m}
$$

Where $\mathrm{I}(\mathrm{Dn})$ is the magnitude of the $\mathrm{n}^{\text {th }}$ harmonic as a percentage of the fundamental (individual distortion). The THD is zero for a perfectly sinusoidal wave. It increases indefinitely as the wave form distortion increases. A THD of 5 percent is commonly cited as the border line between high and low distortion for distribution circuits [14].

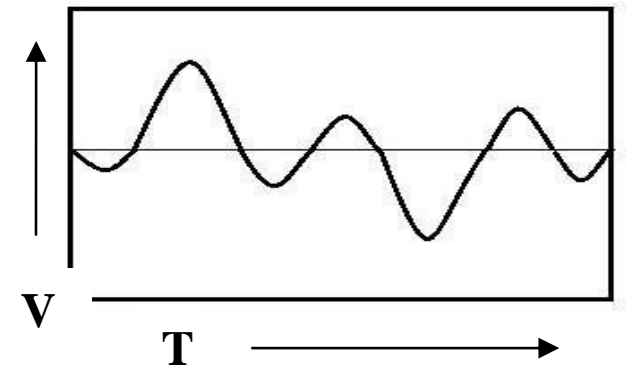

Fig. 7 Harmonic Distortion 


\section{F. Voltage Imbalance}

Voltage unbalance in a three phase system means the magnitudes of three voltages are different and the phase difference between them is not equal to 120 degree. It causes due to unbalanced load in three phase system. The most affected loads are three phase induction machines.

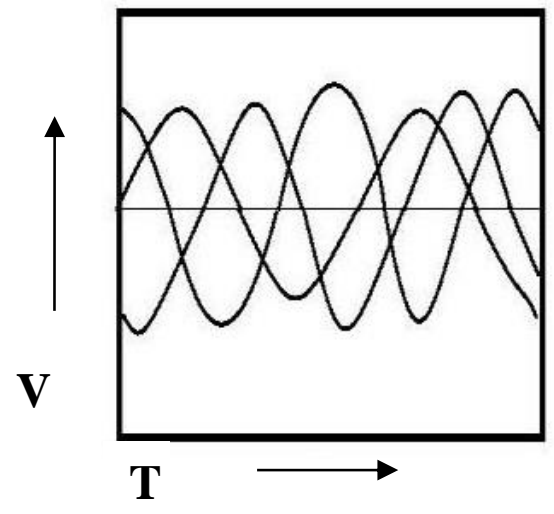

Fig. 8 Voltage Imbalance

G. Noise

Noise is superimposing of high frequency signal on the power supply waveform. There are various causes or sources of noise in the power system like electromagnetic interference, radiations due to welding machines and furnaces etc. Usually noise is not destructive but it may cause data processing errors and disturbance to sensitive equipments.[7]

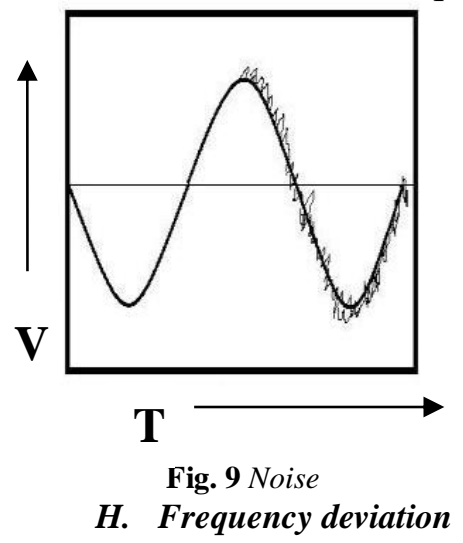

Frequency Deviation is the variation of relatively small frequency value around its nominal or ideal value. Supply frequency is one of the most critical parameter of the power system. Controlling supply frequency is one of the most challenging parts of power system. [14]

\section{ANALYSIS OF GRID STABILITY WITH WIND FORM}

The possible to develop a set of equations describing the behavior of the wind turbine are discussed in this paper. Furthermore, vector control strategy has been examined for controlling active and reactive power of grid, stator and rotor sides. The behavior of the system was investigated during steady state and transient conditions. This paper considers a grid-connected system; a further paper will describe a standalone system with experimental evaluation. [4] 
The model aspects and the impact of wind power onto a weak power system have been described in this paper. A wind system model was presented that takes into account factors such as a rapidly varying turbulence component of the wind and the aerodynamic effects associated to the layout of wind turbines throughout the farm. A test system was used and case studies for different instances of wind farm operation were analyzed, with an aim at evaluating the interaction of the wind farm with the power system. The test system to evaluate the interaction of the wind farm with the power system is as a single-line diagram. Such a system features a substation, represented by a Thevenin equivalent with a short circuit power of 100MVA, which feeds a transmission network operating at $132 \mathrm{kV} / 50 \mathrm{~Hz}$. [15]

- Model Based Predictive Control: A model-based predictive control (MBPC) strategy for the field oriented control of a double output induction generator (DOIG) is presented in this paper. The control region is defined over two wind profiles: average wind speeds below and above equipment rating, subject to assigned constraints of the maximum allowable system frequency fluctuations and the power limit of the wind energy conversion system (WECS). To meet the objectives of maximizing energy capture and alleviation of drive train fatigue loads, controller design is based on perform ability models of the WECS's components. Simulations verify the proposed paradigm achieves regulation of torsional dynamics while maintaining optimal operation. Author stay that Future research will focus on transient analysis and testing the effects of modulation torques such as tower shadowing on the modeling approaches.[16]

- LVRT Capability: A novel approach of pitch regulated wind turbine using intelligent soft starter based induction generator is presented. Neuro Fuzzy approach has been used as intelligent tool in soft starter to estimate thyristors firing angle accurately so as to integrate the generator to the grid smoothly. Various wind turbine models such as $600 \mathrm{~kW}$ and $1000 \mathrm{~kW}$ are taken for simulation and simulation results have been presented to prove the proposed methodology. Low Voltage Ride through (LVRT) capability of proposed methodology in $1 \mathrm{MW}$ wind turbine model is also presented in this paper to prove the reliability of proposed method.[17]

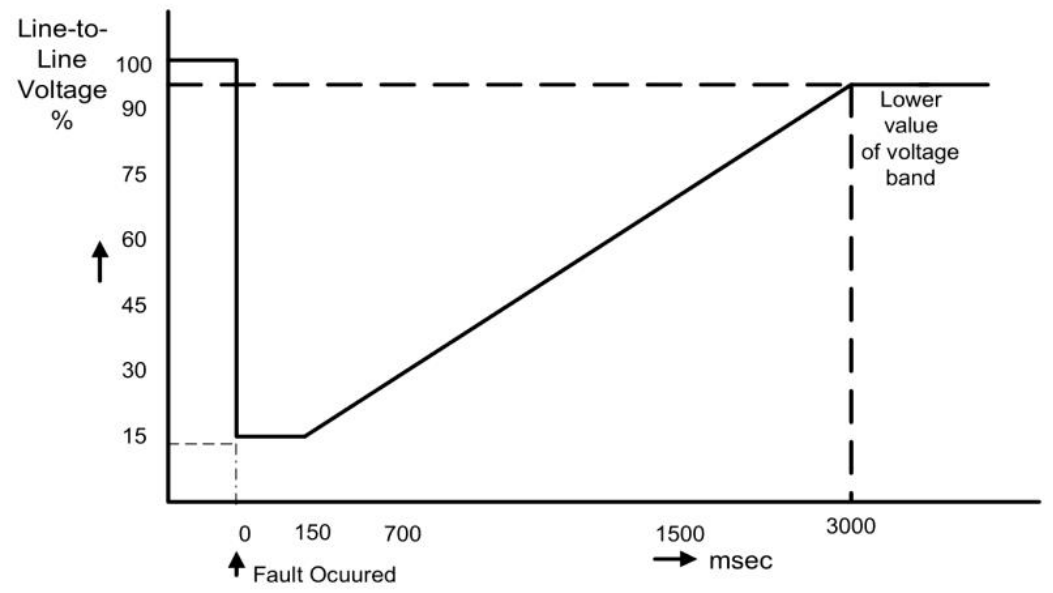


Fig. 10 Low Voltage Ride Through Capability [17]

- Flicker Meter Model: The wind turbine instantaneously generated power and voltages at the point of common connection (PCC) with grid are simulated by considering all the aero dynamical and mechanical effects, which could affect them. The inherent effect of the wind speed on the entire blade swept area is simulated in the model of the wind speed. The generated power is obtained by the simulation of the wind speed time series into a wind turbine model. The flicker meter model which expresses voltage fluctuations is simulated according to the IEC standard 61000-4-15. From simulation results, voltage fluctuations are widely affected by the grid strength and X/R ratio of grid internal impedance. The flicker emission is decreased with higher fault levels. The risk of voltage fluctuation increases in the resistive grids. The wind turbine operating point and the Q-P characteristic of the generator determine the point of minimum flicker emission. The trend of flicker variation with the mean wind speed depends mainly on the wind turbine power curve. The power variability and consequently flicker emission increases with turbulence increase.[21]

- SMES System: The modeling and simulation of a wind farm including a actual wind speed measurements to investigate the fluctuations in the real power of the induction generators. The wind farm's output power oscillates due to the variable wind speed. This coupled with the fact that wind farms are generally connected to weak systems, results in both frequency oscillations and voltage flicker. The simulations show that the SMES can help to improve both SMES system. Transient models for the WECS and SMES system have been developed in EMTP. The study considers the transient stability and the controllability of the real power, which contributes to an overall improvement in the system's performance. [22]

- ATP: The adequacy of Alternative Transients Program (ATP) Draw to accomplish the studies necessary to evaluate the impact of connecting wind farms to power systems, since the elements of the wind farm are adequately modeled. The simulations presented show the possibility to evaluate the consequences of the possible disturbances, as well as to deduce the solutions and verify their use. Further, the developed tools allow the investigation of applying control strategies to the converters taking into consideration the power quality.[23]

- Monte Carlo Simulation: The problem of predicting a wind farm's power generation when no or few statistical data is available is highlighted in this paper. The study is based on a time-series wind speed model and on a simple dynamic model of a doubly-fed induction generator wind turbine including cut-off and cut-in behaviors'. The wind turbine is modeled as a stochastic hybrid system with three operation modes. Numerical results, obtained using Monte- Carlo simulations, provide the annual distribution of a 
wind farm's active power generation. For different numbers of wind turbines, we compare the numerical results obtained using the dynamic model with those obtained considering the wind turbines steady-state power curve. Simulations show that considering the wind turbines dynamics does not significantly enhance the accuracy of the annual distribution of a wind farm generation.[24]

\section{CONCLUSION}

Based on the aforesaid discussion and data about the wind based Distributed Generation system. This can be concluded that Wind based DG with respect to the energy needs and environmental concerns, electricity from wind generators is considered as one of the future solutions. In power system most of the problems occur due to the interconnections of different types of power generators. Therefore, it is challenging to maintain reliable and healthy power system while integrating wind based DG with power grid. In this paper we discussed power quality factors like voltage interruptions, harmonics, flickers, noise etc. This paper gives a survey on impact of wind power on grid stability. As the integration of wind into grid is now increasing day by day, voltage stability is important point of concern. The wind turbine generating system illustrates the electrical performance of the system as it reflects on the grid \& influence voltage stability.

\section{REFERENCES}

[1] T. Ackerman, G. Anderson, L. Sodder (2001), Distributed Generation: A definition, Electric Power Systems Research, vol.57, p.p. 195-204.

[2] Banerjee R (2006), Comparison of options for distributed generation in India. Energy Policy, vol.34, p.p.101-11

[3] Yi Zhang, Student Member, IEEE, and Sadrul Ula, Senior Member,IEEE, Comparison and Evaluation of Three Main Types of Wind Turbines, , B.Chitti Babu, K.B.Mohanty, C.Poongothai.

[4] Performance of Double-Output Induction Generator for Wind Energy Conversion Systems , First International Conference on Emerging Trends in Engineering and Technology.

[5] Sharad W., Mohod, Mohan, V. Aware, -Power Quality Issues and Its Improvement in Wind Energy Generation Interface to Grid Systeml, MIT International Journal of Electrical and Instrumentation Engg., vol.1,no.2,pp.116-122,2011.

[6] C. Tejavoth, M. Trishulapani, V. Rao, Y. Rambabu (July 2013). Power Quality Improvement for Grid Connected Wind Energy System using STATCOM-Control Scheme, IOSR Journal of Engineering (IOSRJEN), ISSN: 2278-8719, Vol. 3, Issue 7, ||V6 || PP 51-57.

[7] A. Almeida, L. Moreira, J. Delgado (2013), Power Quality Problems and New Solutions, ISR Department of Electrical and Computer Engineering University of Coimbra, PloII, 3030-290 Coimbra (Portugal), Accessed on August 2014, pp. 1-9. 
[8] P. Sorensen, N. A. Cutululis, T. Lund, A. D. Hansen, T. Sorensen, J. Hjerrild, M. H. Donovan, L. Christensen, and H. K. Nielsen, "Power Quality Issues on Wind Power Installations in Denmark," IEE Power Engineering Society General Meeting, 2007. , 2007, pp. 1-6.

[9] C. Kocatepe, A.Inan, O. Arikan, R. Yumurtaci, B.Kekezoglu, M. Baysal, A. Bozkurt, and Y. Akkaya, "Power Quality Assessment of Grid-Connected Wind Farms Considering Regulation in Turkey," Renewable and Sustainable Energy Reviews, vol. 13, pp. 2553-2561, 2009.

[10] E. Ghiani, F. Pilo, G. G. Soma, and G. Celli, "Power Quality Measurements Performed on a Large Wind Park at Low an Medium Voltage Level," International Conference on Power Systems Transient, Lyon, France, 2007.

[11] D. Dragomir, N. Golovanov, and P. Postolache, "Overview on the Grid Code Requirements Related to the Connection of Wind Power Plants," 2nd International Comference on Modern Power System MPS. , CLUJ-NAPOCA, Romania, 2008.

[12] H. Emanuel, M. Schellschmidt, S. Wachtel, and S. Adloff, "Power quality measurements of wind energy converters with full-scale converter according to IEC 61400-21," 10th International Conference on Electrical Power Quality and Utilisation, 2009. EPQU 2009. , 2009, pp. 1-7.

[13] N. Golovanov, G. C. Lazaroiu, M. Roscia, and D. Zaninelli, "Integrating RES into the Romanian transport system," IEEE PowerTech Bucharest, 2009, pp. 1-6.

[14] A.Velayutham, (January 2015), Expert talk on Power Quality (PQ) Issues in smart Grid and Renewable Energy Soures, Ex Member,MERC, at SGRES, CPRI, Bangalore.

[15] G. O. Suvire and P. E. Mercado, Senior Member, IEEE, Wind Farm: Dynamic Model and Impact on a Weak Power System Endusa Billy Muhando, , Tomonobu Senjyu, , Eitaro Omine, , Yuri Yonaha, Toshihisa Funabashi, Steady-state and Transient Dynamic Response of GridConnected WECS with Asynchronous DOIG by Predictive Control under Turbulent Inflo.

[16] Endusa Billy Muhando, Student Member, IEEE, Tomonobu Senjyu,Senior Member, IEEE, Eitaro Omine, Student Member, IEEE, Yuri Yonaha, Student Member, IEEE, and Toshihisa Funabashi, Senior Member, IEEE, Steady-state and Transient Dynamic Response of GridConnected WECS with Asynchronous DOIG by Predictive Control under Turbulent Inflow.

[17] L. Rajaji, Dr. C. Kumar, Neuro Fuzzy Soft Starter for Grid Integration with Pitch Regulated Wind Turbine System 5th International Conference on Electrical and Computer Engineering ICECE 2008, 20-22 December 2008, Dhaka, Bangladesh

[18] E. Muljadi A. Ellis Validation of Wind Power Plant Models Federico Milano Assessing Adequate Voltage Stability Analysis Tools for Networks with High Wind Power Penetration.

[19] Bongani Malinga Dr. John E. Sneckenberger, Dr. Ali Feliachi Modeling and Control of a Wind Turbine as a Distributed Resource.

[20] Antonios E. Haniotis, Konstantinos S. Soutis, Antonios G. Kladas and John A. Tegopoulos Grid Connected Variable Speed Wind Turbine Modeling, Dynamic Performance and Control. 
[21] Fengquan Zhou, Géza Joós, Senior Member, IEEE, Chad Abbey, Student Member, IEEE, Lianwei Jiao, Member, IEEE, and Boon Teck Ooi, Fellow, IEEE Use of Large Capacity SMES to Improve the Power Quality and Stability of Wind Farms.

[22] Peter Nielsen, Gert K. Andersen, Knud D.Hagemann, Kenneth Skaug, John Bech, A Performance Oriented Wind Turbine Model for Grid Stability Studies.

[23] A. Samuel Neto, F. A. S. Neves, E. L. R. Pinheiro, R. Gaiba, S. R. Silva, Dynamic Analysis of Grid Connected Wind Farms Using ATP.

[24] A review of grid code technical requirements for wind farms, M. Tsili S. Papathanassiou, School of Electrical and Computer Engineering, National Technical University of Athens (NTUA), 9 Iroon Polytechniou str., Athens 15773, Greece, IET Renew. Power Gener. 2009, Vol. 3, Iss. 3, pp. 308-332.

[25] Alok Kumar Mishra, L. Ramesh S.P. Chowdhury, S. Chowdhury, "Review of Wind Turbine System and Its Impact for grid Stability", Journal of Electrical Engineering,2017, pp.1-13

[26] Mishra, A. K., et al. "Review of wind turbine system and its impact for grid stability." Journal of Electrical Engineering 11.1 (2011): 153-165.

[27] M. Molinas, J. A. Suul, and T. Undeland, "Wind farms with increased transient stability margin provided by a STATCOM," CES/IEEE 5th International Power Electronics and Motion Control Conference, 2006. IPEMC 2006. , 2006, pp. 1-7.

[28] Ackermann T. Wind power in power systems. Chichester: Wiley; 2005.

[29] Annual Report (2016-17) Ministry of New \& Renewable Energy, India,2017 